\title{
Interanimal transfer and chemical events underlying the kindling effect*
}

\author{
JOHN GAITO, ROBERT W. HOPKINS \\ and \\ WAYNE PELLETIER \\ York University, Downsview, Ontario, Canada
}

In three experiments rats, subjected to low-intensity electrical stimulation unilaterally to the amygdala over repeated trials until clonic convulsions resulted, showed the same electrophoretic pattern of the prealbumin range acidic proteins as did nonstimulated controls and rats subjected to stimulation for varying periods prior to convulsions. In a fourth experiment, there were no differences in kindling behavior of recipients injected with soluble proteins from kindled animals, recipients injected with similar material from nonkindled rats, and recipients injected with saline.

In the last 20 years, there have been attempts by many investigators to determine the brain neurochemical events which occur during learning behavior (Gaito, 1966, 1971). Molecular Psychobiology Laboratory personnel at York University have been engaged in this task for 9 years (Gaito, 1972). A major problem in these attempts has been that of ensuring that the control or "nonlearning" animal does not show learning so as to contrast sharply with the "learning" animal. Even though the control animal does not learn the task to which the experimental animal is subjected, he may be learning other things. Thus, it would be more efficacious to choose an event that is similar to learning but one in which control conditions are more adequate. One possibility is that of the "kindling effect."

A group of researchers (Goddard, McIntyre, \& Leech, 1969; McIntyre, 1970) have found that repeated low-level stimulation via implanted electrodes in a number of subcortical sites leads eventually to bilateral clonic convulsions that are of relatively permanent nature. For example, daily administered electrical stimulation to the amygdala produces clonic convulsions on the average in about 15 days. The initial stimulations have little effect on the animal's behavior (Stage 1, normal behavior); with several repetitions, overt indications of seizure activity can be observed, e.g., eyelid blinking, chewing, salivation (Stage 2, behavioral automatisms). With further stimulations, these automatisms culminate in a complete convulsion (Stage 3, clonic convulsions). These convulsions involve the rat's standing on his hindpaws and showing bilateral clonic convulsions of the forepaws, continuing after the stimulation is terminated.

*This research was supported by the President's NRC Fund from York University and a grant from the Ontario Society for Crippled Children. Howard Flock sponsors this paper and takes full editorial responsibility for its contents.
Attending these behavinral changes are neurophysiological modifications (Racine, 1972). First there is the normal electrical pattern. With repeated stimulation, the threshold for an after-discharge (AD) is decreased. Soon the AD appears; it is a simple spike and waveform, $1 \mathrm{cps}$, with a duration of about 6 to $50 \mathrm{sec}$ and a mean amplitude of $702 \mu \mathrm{V}$. The first $\mathrm{AD}$ appears before behavioral automatisms are observed. Upon further stimulation, the waveform becomes more complex and increases occur in frequency, duration, and amplitude. Then an $\mathrm{AD}$ is induced in the contralateral amygdala. At first, the amplitude of this wave is lower than the AD in the ipselateral amygdala. When the two are approximately equal in amplitude, clonic convulsions ensue.

The kindling paradigm was used in the present study. The purpose of this study was twofold: (1) to determine if different electrophoretic patterns of acidic proteins accompanied the three behavioral stages involved in the kindling process-normal behavior, behavioral automatisms, clonic convulsions; (2) to determine if soluble acidic proteins from kindled rats would facilitate kindling when injected into naive recipients.

\section{METHODS AND RESULTS}

Prior to the initiation of formal experiments, brain coordinates similar to those of McIntyre (1970) $(.5 \mathrm{~mm}$ posterior to bregma, $4.5 \mathrm{~mm}$ from midline, $8.5 \mathrm{~mm}$ from skull) were utilized with a number of animals. Brain slices were prepared and stained to determine the location of the implanted electrodes. These histological analyses indicated that the tip of the electrode was in the amygdala. Thus, all experiments utilized these specific coordinates. In all experiments, Wistar strain male rats (between 90 and 160 days of age at the beginning of the experiment) were implanted with bipolar electrodes (Nichrome wire with diamel coating, $.127 \mathrm{~mm}$ in diam, dipped in Epoxylite) into the amygdala. Half of the animals had electrodes inserted into the right hemisphere and half into the left hemisphere. All electrodes were inspected for electrical adequacy before insertion and after sacrificing of the rat. Rats were kindled 6 or more days after surgery.

\section{Experiments 1, 2, and 3}

Six rats (E) were stimulated at 24 -h intervals by a $60-\mathrm{Hz}$ sine wave of $140-\mu \mathrm{A}$ intensity (peak to peak) for $60 \mathrm{sec}$ from a Lafayette sine wave stimulator. Six other littermates (C) were connected to stimulator lead wires but received no stimulation. A response was scored as a clonic convulsion (CC) only if the convulsion continued after termination of the current. After three CCs, at 
Table 1

Mean Values for the Various Stages During Kindling Procedure in Experiment III

\begin{tabular}{|c|c|c|c|c|c|c|c|c|c|c|}
\hline & \multicolumn{5}{|c|}{ VB } & \multicolumn{5}{|c|}{ DB } \\
\hline & 1 & 2 & 3 & 4 & 5 & 1 & 2 & 3 & 4 & 5 \\
\hline & \multicolumn{10}{|c|}{ Semiquantitative Analysis* } \\
\hline $\begin{array}{l}\text { NS } \\
\text { S } \\
\text { BA } \\
\text { CC }\end{array}$ & $\begin{array}{l}2 \\
1 \\
2 \\
1\end{array}$ & $\begin{array}{l}24 \\
23 \\
25 \\
26\end{array}$ & $\begin{array}{l}54 \\
65 \\
57 \\
61\end{array}$ & $\begin{array}{l}36 \\
64 \\
72 \\
40\end{array}$ & $\begin{array}{r}90 \\
102 \\
87 \\
81\end{array}$ & $\begin{array}{r}7 \\
12 \\
18 \\
14\end{array}$ & $\begin{array}{l}22 \\
29 \\
34 \\
30\end{array}$ & $\begin{array}{l}128 \\
137 \\
152 \\
145\end{array}$ & $\begin{array}{l}99 \\
92 \\
88 \\
96\end{array}$ & $\begin{array}{l}148 \\
169 \\
172 \\
161\end{array}$ \\
\hline $\mathrm{CC}$ & \multicolumn{10}{|c|}{ Relative Percentage Analysis $\dagger$} \\
\hline $\begin{array}{l}\text { NS } \\
\text { S } \\
\text { BA } \\
\text { CC }\end{array}$ & $\begin{array}{l}1 \\
1 \\
1 \\
1\end{array}$ & $\begin{array}{r}12 \\
9 \\
11 \\
12\end{array}$ & $\begin{array}{l}28 \\
25 \\
24 \\
29\end{array}$ & $\begin{array}{l}18 \\
24 \\
30 \\
19\end{array}$ & $\begin{array}{l}43 \\
42 \\
36 \\
39\end{array}$ & $\begin{array}{l}2 \\
3 \\
4 \\
3\end{array}$ & $\begin{array}{l}6 \\
6 \\
7 \\
7\end{array}$ & $\begin{array}{l}32 \\
31 \\
32 \\
33\end{array}$ & $\begin{array}{l}25 \\
21 \\
19 \\
21\end{array}$ & $\begin{array}{l}37 \\
39 \\
39 \\
36\end{array}$ \\
\hline
\end{tabular}

*Numbers refer to relative area under densitometric curve $N S$-nonstimulated $S$-stimulated for 3 or more days

†Numbers express the percentage of area under curve $B A$-behavioral automatism stage $C C$-clonic convulsive stage

2 min after the initiation of the trial, $\mathrm{E}$ and $\mathrm{C}$ were sacrificed in liquid nitrogen. The brain was rapidly removed; olfactory bulbs, cerebellum, and brain stem parts below the cerebellum were deleted; the remainder was sectioned in two parts [ventral brain (VB) and dorsal brain (DB)] by a horizontal cut about $2 \mathrm{~mm}$ above the rhinal fissure. Each sample was homogenized in distilled $\mathrm{H}_{2} \mathrm{O}$ and centrifuged at $20,000 \mathrm{xg}$ in a Sorvall centrifuge (HB-4 rotor) for 30 min (Kawakita, 1972). The supernatant containing the soluble proteins was used for the electrophoretic analyses.

Fifty microliters of each supernatant were layered on polyacrylamide gels and run in an electrophoresis apparatus (Davis, 1964), using 10\% and 15\% acrylamide gels (7-cm tubes, pH 9.0, $5 \mathrm{~mA}$ per tube). Gels were stained with $1 \%$ aniline blue black in $7 \%$ acetic acid (30 min), destained electrophoretically, and stored in $7 \%$ acetic acid. This procedure allowed an isolation of acidic proteins of five bands in the prealbumin range (PAR), some of which have been assumed to be specific to the nervous system (Kawakita, 1972). The gels were scanned by a Joyce Loebl chromoscan.

A semiquantitative analysis used the area under each band as the dependent variable for both $10 \%$ and $15 \%$ gel results for VB and DB separately. To eliminate differences in the amounts of acidic protein in each $50 \mu \mathrm{l}$ sample, a second analysis was obtained by dividing each value by the sum of the five bands and multiplying by 100 (relative percentage analysis). Variance analyses indicated significant differences between the five bands (as one would obviously expect) but no differences between kindled and nonkindled rats in all analyses. $\mathrm{E}$ tended to show greater mean values than $\mathrm{C}$ over the five bands in DB with $10 \%$ gels, but the results were not significant $(\mathrm{p}>.05)$.

A second experiment was conducted with six pairs of rats in which the stimulation was $50 \mu \mathrm{A}$; the rats were sacrificed $6 \mathrm{~min}$ after the beginning of the trials following five CCs. The VB and DB samples were slightly different than those in Experiment 1. A horizontal cut was made along the rhinal fissure, and cortical and subcortical tissues down to the diencephalon were peeled off for one sample (VB). The remainder constituted DB.

The soluble proteins were run on longer gels than in Experiment 1, using $100-\mu \mathrm{l}$ samples (14-cm tubes, pH 9.0, $3 \mathrm{~mA}$ per tube, 10\% acrylamide). These gels provide the same basic five-band pattern that was obtained with the short gels; however, the bands are spread out more than with the short gels.

Again no significant results between $\mathrm{E}$ and $\mathrm{C}$ rats occurred in either the semiquantitative or the relative percentage analyses ( $\mathrm{C}$ was greater than $\mathrm{E}$ in the former, but $p>.05$ ). Bands was a significant source of variation in all analyses.

The third experiment was concerned with a chemical analysis of rats at each stage in the kindling process. Eighteen rats were used: two with no stimulation, seven during Stage 1, four when behavioral auiomatisms were well developed, and five immediately after eight CCs.

Electrophoretic procedures were similar to those of Experiment 2. The statistical analyses were as in the previous experiments, and no differences were found between nonstimulated rats, rats stimulated for a number of days, those showing BA, and those sacrificed after eight CCs. The means in Table 1 are typical of the results in Experiments 1 and 2 also.

\section{Experiment 4}

Goddard et al (1969) indicated that stimulation of one amygdala facilitated kindling in the other amygdala (intraanimal transfer or facilitation). Experiment 4 was concerned with the possibility of interanimal transfer.

Thirty Wistar rats had electrodes implanted unilaterally in the amygdala. Ten of these $(\mathrm{C})$ received no stimulation. Twenty rats (E) were stimulated at $50 \mu \mathrm{A}$ - until CC occurred on 5 days. Seventy-two hours later, all rats were sacrificed in a guillotine apparatus. The brains were extracted and stored at $-60^{\circ} \mathrm{C}$ until used. Two brains were homogenized together in 
physiological saline. The homogenates were shaken overnight at $2^{\circ} \mathrm{C}$ and centrifuged at $20,000 \mathrm{x}$ g for $1 \mathrm{~h}$.

Recipient rats had electrodes implanted unilaterally in the amygdala and were used 6 to 24 days later. Each recipient was lightly anesthesized with ether and received $5 \mathrm{ml}$ of supernatant (the equivalent of two brains) from $\mathrm{E}$ or $\mathrm{C}$ rats via an intraperitoneal injection. A third group of rats received saline injections. All recipients were coded and run $72 \mathrm{~h}$ after injection. Each recipient was stimulated at $12-\mathrm{h}$ intervals until five $\mathrm{CCs}$ resulted.

The results are given in Table 2 for number of trials to first $\mathrm{CC}$ and number of trials to first BA. The data were subjected to variance analyses; no significant differences between $\mathrm{E}$ and $\mathrm{C}$ recipients occurred with either dependent variable.

Although no significant differences appeared, there was some tendency for recipient rats that had received injections from nonstimulated rats to be fast kindlers; whereas recipient rats with injections of soluble proteins from kindlers showed a tendency to be slow kindlers. This result suggests an "immunizing type response" but is probably a chance one; however, this possibility should be evaluated in future research.

\section{DISCUSSION}

Goddard et al (1969) reported a mean number of trials to first $\mathrm{CC}$ of 15 with a large sample and a mean of 22 with a smaller sample. Over these four experiments, the mean was 16.4.

Although the five PAR electrophoretic bands showed significant differences in Experiments 1-3, no significant variations in any of the five-band patterns occurred between $\mathrm{E}$ and $\mathrm{C}$ rats, which may mean that there are no differences in acidic protein patterns during the development of kindling. However, it should be recognized that the tissue analyzed was of gross nature. The dorsal brain was of secondary interest. The tissue of primary concern was the ventral brain, because it contained the amygdala, but the amygdala constituted only a small part of the total mass in VB. Thus, changes might have occurred in the amygdala but were not detected because of the greater amount of other tissue present in VB.

It is important to recognize that, even though these studies
Table 2

Experiment IV Data*

\begin{tabular}{cccccc}
\hline & E & C & Cs \\
\hline \multicolumn{5}{c}{ Mean Number of Trials to First CC } \\
22 & $(10)$ & 12 & $(5)$ & 26 & $(6)$ \\
\multicolumn{2}{l}{ Mean Number of Trials to First of Two Consecutive BAs } \\
16 & $(10)$ & 8 & $(5)$ & 19 & $(6)$ \\
\hline
\end{tabular}

*Number of rats in parentheses. E-rats injected with soluble protein from kindled animals; $C$-rats injected with soluble protein from nonkindled animals; Cs-rats injected with phyriological saline.

showed no differences in acidic proteins of the whole cell, there are probably differences in total proteins from whole cell (which were not evaluated in the present studies). Previous work by a number of researchers with convulsing animals indicated a temporary reduction in RNA and proteins with a rapid return to the normal steady state level (Gaito, 1966).

As with the chemical analyses, the recipients in Experiment 4 were not separated relative to the source of the material injected in the dependent variables utilized. No differences were attributable to kindled or nonkindled sources or to donor or nondonor (saline) sources.

\section{REFERENCES}

Davis, B. J. Disc electrophoresis. II. Method and application to human serum proteins. Annals of the New York Academy of Sciences, 1964, 121, 404-427.

Gaito, J. Molecular psychobiology. Springfield, Ill: Thomas, 1966.

Gaito, J. DNA complex and adaptive behavior. Englewood Cliffs, N.J: Prentice-Hall, 1971.

Gaito, J. Macromolecules and brain function. In J. Gaito (Ed.), Macromolecules and behavior. 2nd ed. New York: Appleton-Century-Crofts, 1972.

Goddard, G. V., McIntyre, D. C., \& Leech, C. K. A permanent change in brain function resulting from daily electrical stimulation. Experimental Neurology, 1969, 25, 295-330.

Kawakita, H. Immunochemical studies on the brain specific protein. Journal of Neurochemistry, 1972, 19, 87-93.

McIntyre, D. C. Differential amnestic effect of cortical vs amygdaloid elicited convulsions in rats. Physiology \& Behavior, 1970, 5, 747-753.

Racine, R. J. Modification of seizure activity by electrical stimulation: II. Motor seizure. Electroencephalography \& Clinical Neurophysiology, 1972, 32, 281-294.

(Received for publication February 9, 1973.) 